\title{
Accuracy of intraoperative estimation of femoral stem anteversion in cementless total hip arthroplasty by using a digital protractor and a spirit level
}

\author{
Anuwat Pongkunakorn * (D), Nawakun Phetpangnga and Narawit Kananai
}

\begin{abstract}
Background: The femoral component anteversion during surgery is traditionally assessed by a visual assessment of the surgeon and has proven to be imprecise. We sought to determine the accuracy of a digital protractor and a spirit level to measure the stem anteversion during cementless THA.

Methods: A prospective study was conducted among 107 patients (114 hips) who underwent primary cementless THA via posterolateral approach. A pipe with a spirit level was attached to the tibial tubercle and intermalleolar midpoint. While the leg was held perpendicularly to the floor, stem anteversion was estimated by 3 methods: method A by visual assessment; method B by a digital protractor alone; and method $\mathrm{C}$ by a digital protractor combined with a spirit level. The angles were compared with the true anteversion measured by postoperative $\mathrm{CT}$ scan.

Results: The average anteversion by method $C\left(22.8^{\circ} \pm 6.9^{\circ}\right.$, range $-2^{\circ}$ to $\left.40^{\circ}\right)$ was significantly lower than method A $\left(24.6^{\circ} \pm 5.2^{\circ}\right.$, range $0^{\circ}$ to $\left.30^{\circ}\right)(p=0.033)$, but not different from the true anteversion $\left(22.1^{\circ} \pm 8.2^{\circ}\right.$, range $-5.4^{\circ}$ to $\left.43.1^{\circ}\right)(p=0.445)$. There were no significant differences between method $B\left(23.2^{\circ} \pm 8.2^{\circ}\right.$, range $-4^{\circ}$ to $\left.45^{\circ}\right)$ and method $\mathrm{A}, \mathrm{C}$ or the true anteversion. The mean deviation of the intraoperative estimation from the true anteversion was $0.8^{\circ} \pm 3.7^{\circ}$ (range $-7.1^{\circ}$ to $8.0^{\circ}$ ) by method $C_{;} 1.2^{\circ} \pm 5.1^{\circ}$ (range $-8.8^{\circ}$ to $14.3^{\circ}$ ) by method $B_{;}$and $2.5^{\circ} \pm 7.4^{\circ}$ (range $-19.0^{\circ}$ to $16.0^{\circ}$ ) by method A. Estimation error within $5^{\circ}$ was found in 107 hips (93.9\%) with method $C_{;} ; 86$ hips (75.4\%) with method B; and 59 hips (51.8\%) with method A.

Conclusion: Accurate estimation of stem anteversion during cementless THA can be determined intraoperatively by the use of a digital protractor and a spirit level.

Trial registration: Thai Clinical Trials Registry (TCTR 20180326003). Registered on 20 March 2018. Retrospectively registered.
\end{abstract}

Keywords: Femoral stem anteversion, cementless total hip arthroplasty, digital protractor, spirit level

\footnotetext{
* Correspondence: dranuwat@hotmail.com

Department of Orthopaedic Surgery, Lampang Hospital and Medical

Educational Center, Lampang, Thailand
}

(c) The Author(s). 2021 Open Access This article is licensed under a Creative Commons Attribution 4.0 International License, which permits use, sharing, adaptation, distribution and reproduction in any medium or format, as long as you give appropriate credit to the original author(s) and the source, provide a link to the Creative Commons licence, and indicate if changes were made. The images or other third party material in this article are included in the article's Creative Commons licence, unless indicated otherwise in a credit line to the material. If material is not included in the article's Creative Commons licence and your intended use is not permitted by statutory regulation or exceeds the permitted use, you will need to obtain permission directly from the copyright holder. To view a copy of this licence, visit http://creativecommons.org/licenses/by/4.0/ The Creative Commons Public Domain Dedication waiver (http://creativecommons.org/publicdomain/zero/1.0/) applies to the data made available in this article, unless otherwise stated in a credit line to the data. 


\section{Introduction}

Successful total hip arthroplasty (THA) depends on an accurate placement of the femoral and acetabular components [1,2]. This accuracy would ensure mating of both components without impingement throughout the hip motion and requires a method to create the combined anteversion. Preparing the femur first has been recommended in cementless THA to allow the surgeon to adjust the cup anteversion according to stem anteversion in the relatively inflexible anatomy of the proximal femur [3]. The femoral component anteversion during the surgery is traditionally assessed by a visual estimation of the surgeon for the angle between the leg axis and the femoral stem axis after flexing the knee and placing the leg vertically. This technique has proven to be imprecise.

Wines and McNicol [2] studied the difference between the surgeons' intraoperative assessment and the CT measurement and found a precision of $10.4^{\circ}$ in 111 hips with a range of $25^{\circ}$ underestimation to $30^{\circ}$ overestimation. Dorr et al [4] found a poor correlation of the surgeon's estimation in 109 hips and a precision of $11.3^{\circ}$. Some investigators used a manual goniometer to improve the precision and found a mean error of $7.3^{\circ}$ [5], or estimation error $\geq 5^{\circ}$ in $28 \%$ of the hips [6]. Some surgeons applied a digital protractor or a spirit level to aim the angles of the acetabular component and reduce outliers significantly [7-10]. There is no previous study regarding the accuracy of the cementless femoral component placement by using such devices. We sought to determine the validity of a digital protractor and a spirit level to measure the femoral stem anteversion during cementless THA.

The purposes of this study were (1) to evaluate the accuracies of intraoperative estimation of cementless femoral stem anteversion by using a digital protractor with or without a spirit level comparing with the conventional method that used visual estimation, and (2) to examine the factors that influenced the angle overestimation and underestimation within $5^{\circ}$ of this new estimating method.

\section{Methods}

A prospective study was conducted among the patients with hip osteoarthritis and femoral neck fractures who underwent primary cementless THA via posterolateral approach by one experienced surgeon between July 2017 and June 2019. Exclusion criteria were patients with previous ipsilateral tibial fractures, total knee arthroplasties and knee deformity with a tibio-femoral angle more than $5^{\circ}$ varus or $15^{\circ}$ valgus. The trial was approved by the institutional review board (Code 42/60) and registered in the Thai Clinical Trials Registry. All patients gave their written informed consent prior to inclusion.

\section{Surgical Techniques}

The surgery was performed via posterolateral approach. The patient was positioned in the lateral decubitus. The leg was put in a stockinette and an EKG electrode (3M Red Dot, USA) was attached to the medial $1 / 3$ of the tibial tubercle. Two plastic pipe clips (Thai Pipe, Thailand) were attached to the anterior part of the shin with nylon cable ties. The base of one clip was positioned at the midpoint of the most medial and most lateral points of the malleoli and the other was locked onto the Red Dot electrode. An aluminium pipe (Yunteng self picture monopod YT-188, China) was gently pressed over both clips until the bilateral grooves of the pipe were snugly captured between the clip edges. This pipe would represent the mechanical axis of the tibia. A spirit level (Haccury YK-3, China) was glued to the base of another pipe clip, and then connected to the pipe by pressing the clip over the pipe (Fig. 1).

When the trial stem was inserted, the femur was internally rotated with knee flexion. Three methods for estimating the stem anteversion were performed sequentially. Method A by visual estimation, the surgeon assessed the angle between the leg axis and the axis of metal rod of the stem inserter handle by eye (Fig 2a). Method B by digital protractor alone, the assistant placed the leg vertically until the surgeon approved its position by visualization, without any concern to the spirit level. A digital protractor (Etopoo DC18, China)

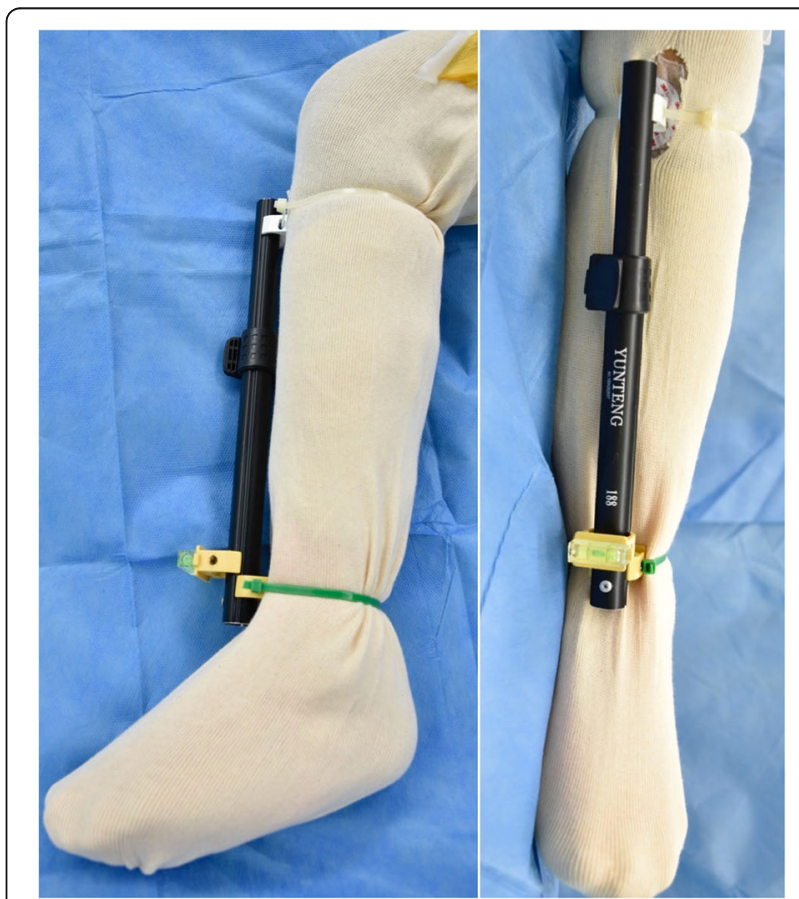

Fig. 1 The aluminium pipe with a spirit level represented the mechanical axis of the tibia by its attachment to the intermalleolar midpoint and the medial $1 / 3$ of the tibial tubercle 

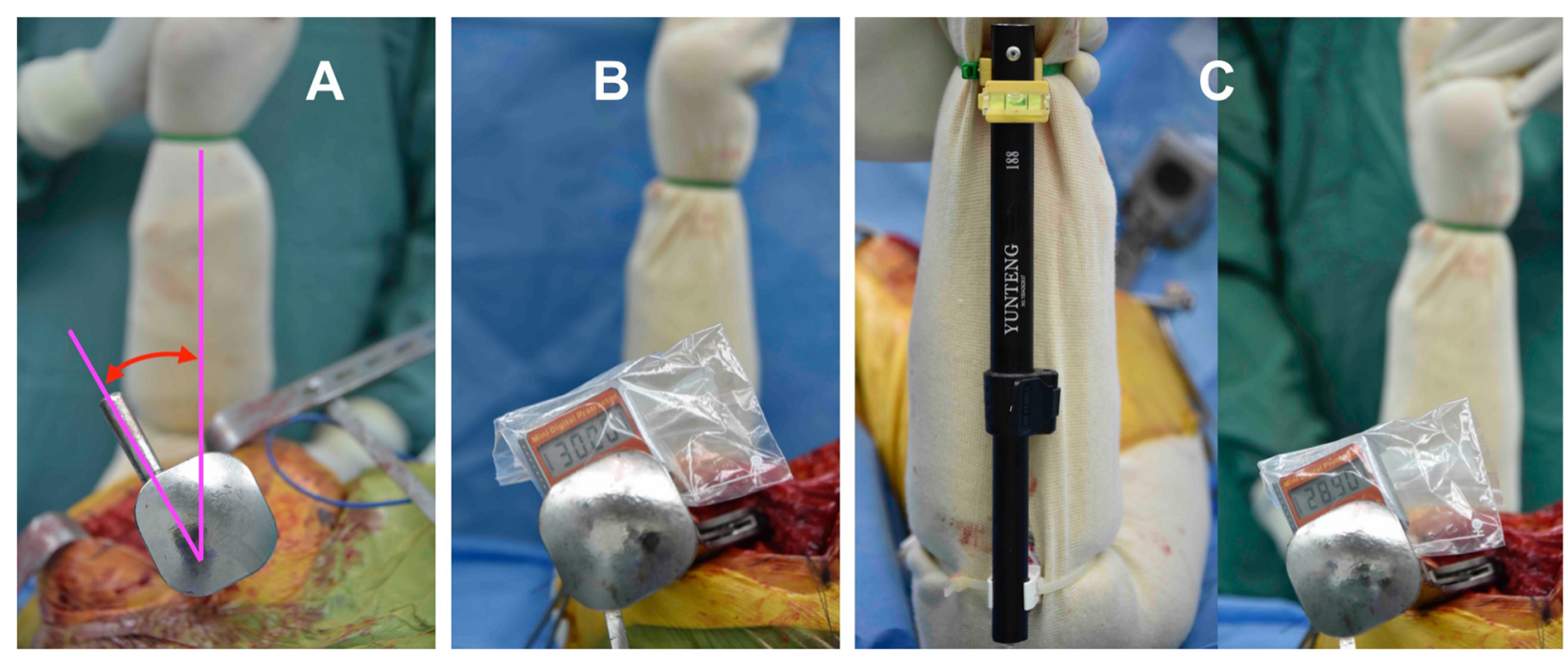

Fig. 2 During trial stem insertion, the femur was internally rotated with knee flexion. Three methods for estimating the stem anteversion were performed sequentially. Method A by visual estimation (a); method B by a digital protractor alone (b); and method C by a digital protractor combined with a spirit level (c)

was placed on the flat surface of the stem handle and recorded as an estimated stem anteversion (Fig 2b). Method $\mathrm{C}$ by digital protractor and spirit level, the assistant internally rotated the leg until a bubble in the spirit level was centered. The stem anteversion was then measured by placing a digital protractor on the handle (Fig 2c).

Demographic data included patient age, gender, body mass index (BMI), diagnosis and stem type. The intraoperative estimation of stem anteversion angles by method $\mathrm{A}, \mathrm{B}$ and $\mathrm{C}$ were recorded. All patients received CT scans postoperatively at 4-5 days, in supine position. The scans were obtained from the acetabulum to the proximal tibia with a 1.5-mm thickness using Philips Ingenuity Core 128 (Cleveland, USA). True stem version was defined as the angle between a line through the center of the neck of the femoral prosthesis and the posterior condylar line [2]. The knee alignment was measured as tibio-femoral angle in the scout view. Two intramedullary midpoints were marked at a $10-\mathrm{cm}$ distance from the knee joint surfaces, one at the distal shaft of the femur and the other at the proximal shaft of the tibia. The angle between the lines drawn from the center of the bases of the tibial spines to both midpoints was defined as a tibio-femoral angle [11].

All radiographic assessments were independently performed by 2 orthopaedic residents, who were not involved with the surgery and repeated in a blind manner 4 weeks later. The average of 4 measurements was used for data analysis. Inter-observer and intra-observer measurement reliabilities were determined with intraclass correlation coefficients (ICC) using the absolute agreement and 2-way random-effects model. ICC values $<0.5$ indicated poor reliability, $0.5-0.74$ moderate, $0.75-$ 0.9 good, and $>0.90$ indicated excellent reliability [12].

The sample size was calculated to detect a significant difference in percentages of hips with intraoperative estimation error within $5^{\circ}$. According to the results in 25 hips of our pilot study using the traditionally visual estimation technique, $52 \%$ (13 hips) had an estimation error within $5^{\circ}$. We hypothesized that our method could achieve this goal in $90 \%$ of hips. With a two-sided type I error level of 0.05 and a $90 \%$ statistical power of detection in a two-dependent proportions formula, the sample size was 100 hips.

The primary outcome was the percentage of stem placements with an error within $5^{\circ}$. The secondary outcome was the deviation degree of the estimated stem anteversion from the true stem anteversion. The Shapiro-Wilk test for normal distribution was used prior to further statistical analysis. Continuous data were analyzed by using the t-test and Mann-Whitney U test. Categorized data were analyzed by using the exact probability test. Correlation between the estimated and true anteversion was analyzed by the Pearson correlation coefficient. Angle overestimation and underestimation were defined when the estimated anteversion was above and below the CT measurement by more than $1^{\circ}$ respectively. We evaluated the factors that influenced the angle overestimation and underestimation in method $\mathrm{C}$ by using multivariate regression analysis. The statistical analyses were performed using STATA version 10.1 (Stata Corp LP, College Station, Texas, USA) and a pvalue of $<0.05$ was considered significant. 


\section{Results}

There were 110 patients (117 hips) enrolled in the study. Two hips were excluded due to severe varus knee deformity and one hip had previous tibial fracture. There were 64 men (68 hips) and 43 women (46 hips) enrolled in the final analysis. The mean age was $56.8 \pm 10.1$ years (range, 25-80). Most of the diagnoses were osteonecrosis of the femoral head (53 hips, 46.5\%), primary osteoarthritis (21 hips, 18.4\%) and femoral neck fracture (20 hips, 17.5\%). Avenir stems (Zimmer Biomet, Warsaw, Indiana, USA) were implanted in 48 hips (42.1\%), Excia stems and Metha stems (Aesculap, Tuttlingen, Germany) in 57 hips (50.0\%) and 9 hips (7.9\%), respectively (Table 1$)$.

The average stem anteversion by method $\mathrm{A}$ was $24.6^{\circ}$ $\pm 5.2^{\circ}$ (range, $0^{\circ}$ to $30^{\circ}$ ); by method $\mathrm{B}$ was $23.2^{\circ} \pm 8.2^{\circ}$ (range, $-4^{\circ}$ to $45^{\circ}$ ); by method $\mathrm{C}$ was $22.8^{\circ} \pm 6.9^{\circ}$ (range, $2^{\circ}$ to $40^{\circ}$ ) and the true anteversion angle was $22.1^{\circ} \pm 8.2^{\circ}$ (range, $-5.4^{\circ}$ to $43.1^{\circ}$ ). Angles by method A were significantly higher than by method $\mathrm{C}(\mathrm{p}=0.033)$ and the true anteversion $(\mathrm{p}=0.006)$.

Interestingly, the estimated angle by a digital protractor combined with a spirit level was not significantly different from the true anteversion angle $(\mathrm{p}=0.445)$. Likewise, non-significant differences were demonstrated when compared between the stem anteversion by a

Table 1 Patients' baseline characteristics ( $n=114$ hips).

\begin{tabular}{ll}
\hline Data & Number (\%) \\
\hline Age (year) & \\
mean (SD) & $56.8(10.1)$ \\
range & $25-80$ \\
Gender male : female & $64: 43$ \\
Body mass index (kg/m $\left.{ }^{2}\right)$ & \\
mean (SD) & $22.7(3.7)$ \\
range & $15.8-35.0$ \\
Diagnosis: & \\
Osteonecrosis of femoral head & $53(46.5 \%)$ \\
Primary osteoarthritis & $21(18.4 \%)$ \\
Femoral neck fracture & $20(17.5 \%)$ \\
Hip dysplasia & $12(10.6 \%)$ \\
Post-traumatic osteoarthritis & $5(4.4 \%)$ \\
Inflammatory joint disease & $3(2.6 \%)$ \\
Stem type N (\%) & \\
Excia (Aesculap) & $57(50.0 \%)$ \\
Avenir (Zimmer-Biomet) & $48(42.1 \%)$ \\
Metha (Aesculap) & $9(7.9 \%)$ \\
Tibio-femoral angle ${ }^{a}$ & \\
mean (SD) & $5.1^{\circ}\left(3.2^{\circ}\right)$ \\
\hline & $-2.9^{\circ}$ to $11.9^{\circ}$ \\
\hline pange &
\end{tabular}

a a positive value represents valgus, and a negative represents varus alignment digital protractor alone and those by visual assessment $(\mathrm{p}=0.141)$; by a digital protractor combined with a spirit level $(\mathrm{p}=0.695)$; as well as the true anteversion angle $(\mathrm{p}=$ 0.284) (Fig 3).

The mean deviation of the intraoperatively estimated anteversion from the true anteversion was $0.8^{\circ} \pm 3.7^{\circ}$ ( $95 \%$ CI $0.1^{\circ}$ to $1.5^{\circ}$, range $-7.1^{\circ}$ to $8.0^{\circ}$ ) by method C; $1.2^{\circ} \pm 5.1^{\circ}\left(95 \% \mathrm{CI} 0.2^{\circ}\right.$ to $2.1^{\circ}$, range $-8.8^{\circ}$ to $\left.14.3^{\circ}\right)$ by method B; and $2.5^{\circ} \pm 7.4^{\circ}$ (95\% CI $1.1^{\circ}$ to $3.9^{\circ}$, range $-19.0^{\circ}$ to $16.0^{\circ}$ ) by method A. Estimation error within $5^{\circ}$ was found in 86 hips $(75.4 \%)$ with using digital protractor alone; significantly lower than $93.9 \%$ (107 hips) by using both digital protractor and spirit level $(\mathrm{p}<$ 0.001 ); but significantly higher than $51.8 \%$ (59 hips) by visual assessment $(\mathrm{p}<0.001)$ (Fig 4$)$. In other words, estimation error $>5^{\circ}$ was most commonly found in the visual assessment method. This risk could be minimized by a digital protractor with or without a spirit level. With digital protractor and spirit level method, the risk difference was $-0.42(95 \% \mathrm{CI}-0.52$ to -0.32$)$ and the risk ratio was $0.13(95 \%$ CI 0.06 to 0.27$)(\mathrm{p}<0.001)$. With digital protractor alone, the risk difference was -0.24 (95\% CI -0.36 to -0.12$)$ and the risk ratio was 0.51 (95\% CI 0.35 to 0.74$)(\mathrm{p}<0.001)$.

The Pearson correlation coefficient of the true anteversion and the estimated anteversion was 0.456 for method A; 0.808 for method B; and 0.896 for method C (Fig 5) with a significant correlation between the measurements $(p<0.001)$. The ICC for intra- and interobserver reliability of anteversion measurements were 0.98 and 0.98 , respectively. The ICC for intra- and interobserver reliability of tibio-femoral angle measurements were 0.91 and 0.73 , respectively. Among the factors analyzed using regression analysis in method $\mathrm{C}$, only the tibio-femoral angle significantly influenced the angle overestimation within $5^{\circ}(\mathrm{p}=0.008)$ (Table 2). No factors were identified to influence angle estimation in hips with underestimation. Hips with an error within $5^{\circ}$ had the average tibio-femoral angle of $4.5^{\circ} \pm 2.6^{\circ}$. Hips with an overestimation $>5^{\circ}$ and underestimation $>5^{\circ}$ had the mean tibio-femoral angle of $7.9^{\circ} \pm 3.1^{\circ}(\mathrm{p}<0.001)$ and $2.4^{\circ} \pm 3.4^{\circ}(\mathrm{p}=0.072)$, respectively. There was one dislocation but no surgical site infection postoperatively. The average duration of follow-up was $27 \pm 7$ months (range, 16 to 39).

\section{Discussion}

Currently, computer navigation is the most accurate method to measure the femoral stem anteversion intraoperatively with a precision of $5^{\circ}$ and no outliers beyond $6^{\circ}$ [3]. Interestingly, other digital devices have not been utilized to improve this estimation error during cementless femoral prosthetic implantation. We investigated whether using a digital protractor and a spirit level 


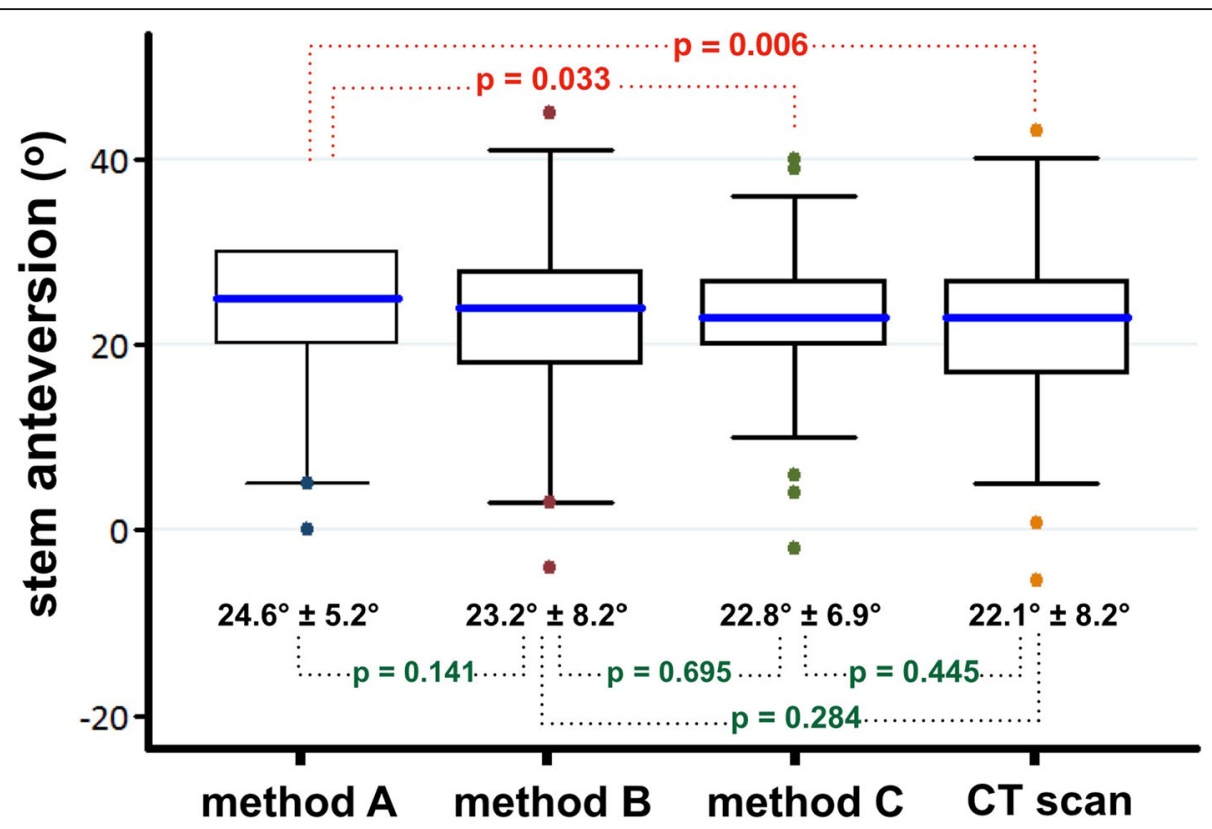

Fig. 3 Anteversion angles of femoral component, comparing between the method $\mathbf{a}, \mathbf{b}, \mathbf{c}$ and $C$ scan. Boundaries of the boxes, $25^{\text {th }}$ and $75^{\text {th }}$ percentiles; horizontal lines inside the boxes, median; whiskers and large dots, maximum and minimum; dotted line, statistical comparison between mean values of the paired methods

provided the technical ability for the surgeon to assess the anteversion of the cementless stem intraoperatively with the target of $5^{\circ}$ estimation error.

Assessment of the femoral component anteversion during the surgery by visual estimation found in this study had a precision of $7.4^{\circ}$ with a range of $19^{\circ}$ underestimation to $16^{\circ}$ overestimation. Estimation error within $5^{\circ}$ was found in only $52 \%$ of hips. Concordance with the previous studies that found the precision of $10.4^{\circ}-11.3^{\circ}$ $[2,4]$. Placing a digital protractor on the trial stem handle could improve the precision to be $5.1^{\circ}$ with a range of $9^{\circ}$ underestimation to $14^{\circ}$ overestimation, and $75 \%$ of hips had an estimation error within $5^{\circ}$. The risk of estimation error $>5^{\circ}$ was reduced by $49 \%$ and the absolute difference was $-24 \%$. Using this technique in an estimated 4 THAs would prevent 1 unacceptable estimation error.

The best outcomes belonged to the method that used both digital protractor and spirit level with a precision of $3.7^{\circ}$. The mean absolute value of error was $0.8^{\circ}$, range from $7^{\circ}$ underestimation to $8^{\circ}$ overestimation, and $94 \%$ of stems had an error within $5^{\circ}$. The risk of estimation error $>5^{\circ}$ was significantly reduced by $87 \%$ and the absolute difference was $-42 \%$. Using this method in an estimated 2 THAs would prevent 1 unacceptable estimation error. Correlation coefficient between the estimated angle by these devices and the true anteversion by $\mathrm{CT}$ scan revealed a high positive correlation [13]. This significant benefit affirmed the same findings of our previous clinical trial in 31 patients with femoral neck fractures who underwent cemented bipolar hemiarthroplasty [14]. We found this method could improve surgeons' estimation of cemented stem anteversion with the mean absolute error of $-0.2^{\circ}$ (SD $3.0^{\circ}$, range $-5.4^{\circ}$ to $7.0^{\circ}$ ) and 28 stems $(90.3 \%)$ had an error within $5^{\circ}$. Surgeon overestimation and underestimation $>5^{\circ}$ was found in 1 hip (3.2\%) and 2 hips (6.4\%) respectively.

Two reasons might explain these precise outcomes. The first explanation is the accuracy and precision of a digital protractor with $+/-0.2^{\circ}$ of error guaranteed by the manufacturer. Powerful built-in magnets on its base secured the attachment to the iron surface of the stem handle. It showed the real-time degree of stem anteversion relative to the floor when the leg was held in vertical position. This device was more user-friendly than a manual goniometer which required approximation of one arm parallel with the lower-leg axis and the other arm parallel with the trial-stem axis. Hirata et al [5] used a manual goniometer to estimate the intraoperative stem anteversion in cementless THA. They reported an average error of $7.3^{\circ}$ and error within $5^{\circ}$ was found in $61 \%$ of 73 hips. Likewise, Lee et al [6] found the mean absolute value of discrepancy of $4.5^{\circ}$ and the discrepancy was $<5^{\circ}$ in 48 hips (72\%). Whereas estimated stem anteversion by digital protractor alone in the current study had an average error of $1.2^{\circ}$ and estimation error within $5^{\circ}$ was found in $75 \%$ of hips.

Secondly, previous literature has shown that the medial $1 / 3$ of the tibial tubercle was an average of $4 \mathrm{~mm}$ lateral to the anteroposterior axis of the tibial component 

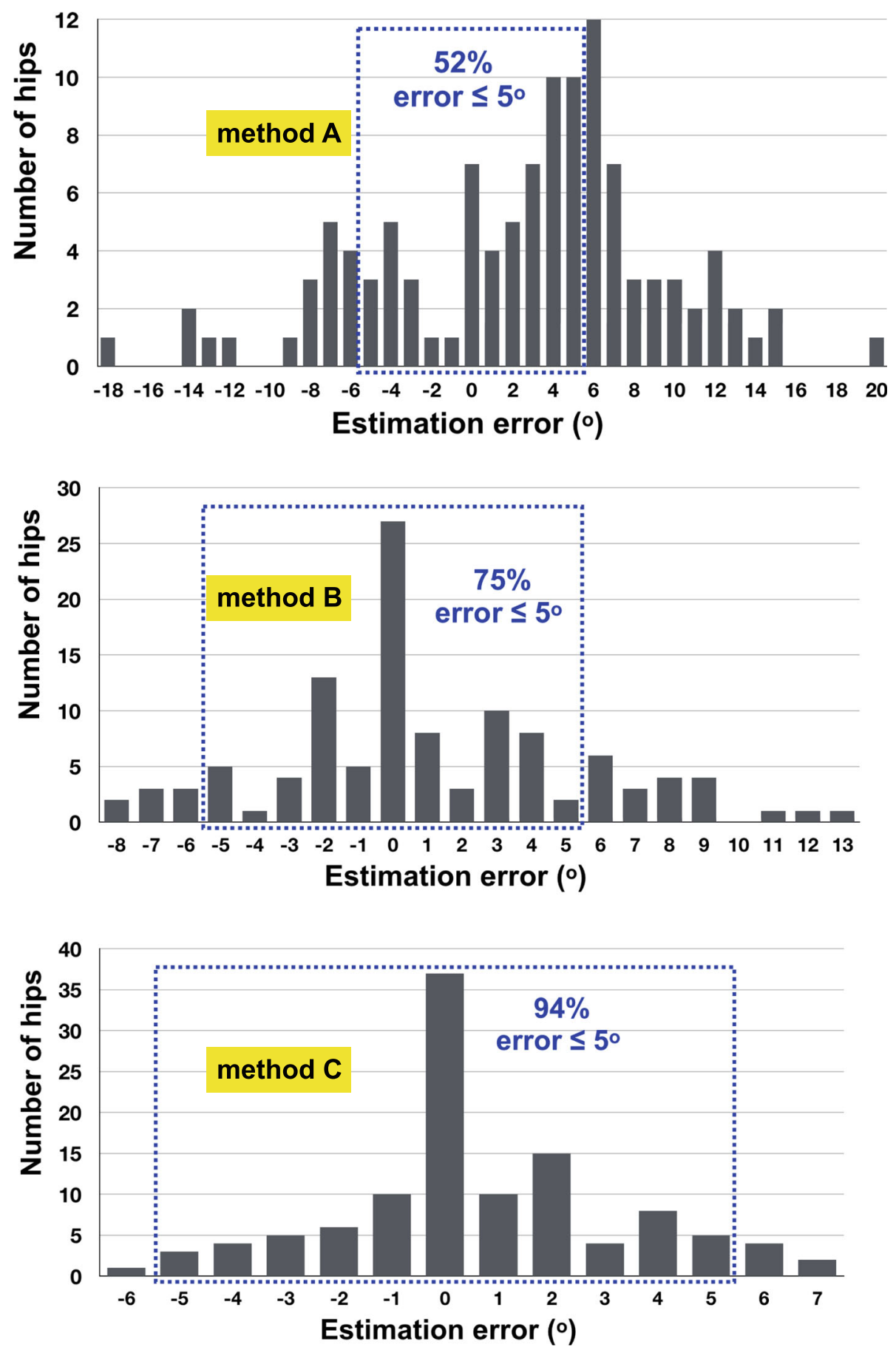

Fig. 4 Distribution of errors in intraoperative estimation from the true anteversion by $C T$ scan of the method $\mathbf{a}, \mathbf{b}$ and $\mathbf{c}$. The dotted zone represents the percentage of stems with errors within $5^{\circ}$. Method A 52\%; method B $75 \%$; and method C 94\%

during total knee arthroplasty [15], whereas the intermalleolar midpoint was an average of $4.5 \mathrm{~mm}$ lateral to the center of the ankle [16]. The aluminium pipe that was connected between these two points of the leg in this study should represent the mechanical axis of tibia. While the knee was flexed and the femur was internally rotated to position the tibia perpendicularly to the floor, the medial joint space should be widened due to the stretching of the medial collateral ligament. This phenomenon might reduce the constitutional varus alignment of the tibial articular surface and its mechanical axis became perpendicular to the posterior condylar 


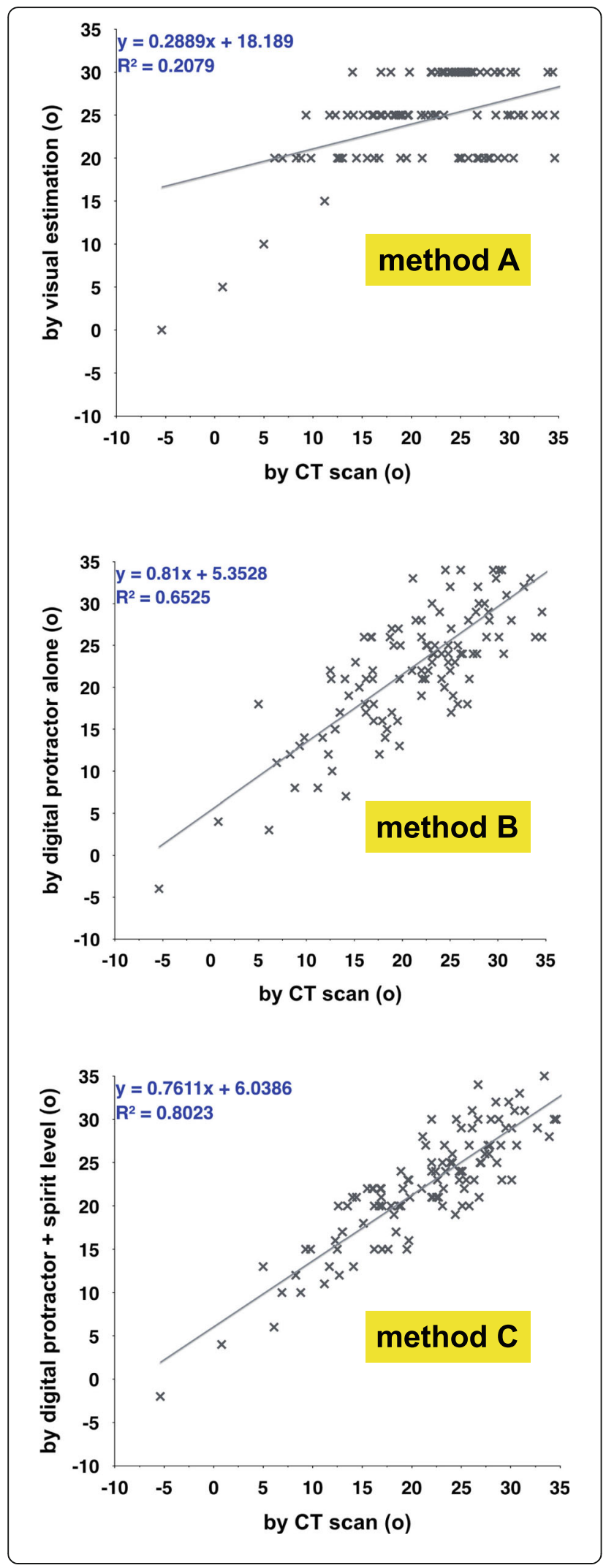

Fig. 5 Intraoperative estimation of stem anteversion compared with CT scan shows a low positive correlation in method $\mathbf{a}(r=0.456)$, but high positive correlations in method $\mathbf{b}(r=0.808)$ and method $\mathbf{c}$ $(r=0.896)$. A solid line represents the linear regression between the estimated and true anteversion $\left(r^{2}\right)$

axis of the femur. While the leg was held upright and the bubble of the spirit level was centered, the posterior condylar axis should be parallel with the floor. This assumption was confirmed by Hirata et al [5] who found that the degree of surgeon error for intraoperative estimation of stem anteversion was significantly influenced by the grade of knee osteoarthritis. Surgeons tended to overestimate in the valgus knee and underestimate in the varus knee. Similarly, our study found that the angle overestimation was significantly influenced by the tibio-femoral angle. Hips with angle overestimation $>5^{\circ}$ had the mean tibiofemoral angle significantly higher, or more valgus, than those with an estimation error within $5^{\circ}$.

There are some limitations to the present study. Firstly, we investigated only on the posterolateral approach in which the leg was turned upright to easily see the centralized-bubble position of the spirit level at the ankle. If the patient was operated in the supine position, surgeons may visualize the femur in a different plane. Likewise, the precision of measurement might differ if we use the direct lateral approach in lateral decubitus, although a previous study found no significant difference in the error measurements for femoral component version by visual estimation when the posterior and modified Hardinge approaches were compared [2]. Secondly, the tibio-femoral angles of the patents in our study were slightly valgus. The precision of this method might not be extrapolated to those with severe knee deformities. Finally, all THAs were performed by the same experienced surgeon. The precision of surgeon estimations can vary from surgeon to surgeon and might be different from those of the surgeon in this study. However, Meermans et al [7] found no difference in the number of safe zone outliers for acetabular component inclination between different surgeons with the use of a digital protractor. To the best of our knowledge, this is the first clinical study that confirms the benefits of a digital protractor and a spirit level to assess the intraoperative anteversion of the femoral component during cementless THA.

The advantages of this novel technique are the high accuracy rates to provide the intra-operative information of stem anteversion which can be used with different stem handles. The surgeon can adjust the anteversion more accurately to achieve the target angle during surgery in a non-invasive, low-cost and time-efficient way. It can reduce the number of anteversion outliers in surgeons with different volumes of practice. Nevertheless, 
Table 2 Factors influencing the angle overestimation and underestimation within $5^{\circ}$ in method $\mathrm{C}$, analyzed by using multivariate regression.

\begin{tabular}{|c|c|c|}
\hline Factors & $\begin{array}{l}\text { Overestimation within } 5^{\circ} \\
\text { ( } n=42 \text { hips) } \\
p \text {-value }\end{array}$ & $\begin{array}{l}\text { Underestimation within } 5^{\circ} \\
\text { ( } n=28 \text { hips }) \\
p \text {-value }\end{array}$ \\
\hline Age & 0.460 & 0.843 \\
\hline Sex & 0.925 & 0.893 \\
\hline Body mass index & 0.773 & 0.984 \\
\hline Diagnosis & 0.652 & 0.955 \\
\hline Stem type & 0.776 & 0.866 \\
\hline True anteversion & 0.549 & 0.671 \\
\hline Tibio-femoral angle & 0.008 & 0.164 \\
\hline
\end{tabular}

its disadvantages seem to be the prepared invention of a rod connecting between the tibial tubercle and the intermalleolar midpoint, and its attachment mechanism with the leg and a spirit level. We found that the cable ties and pipe clips were suitable for this purpose. Additionally, the surgical exposure and soft tissue release must be adequate in order to easily hold the leg in the vertical position during the angle estimation. This technique may not be appropriate with surgeons who prefer minimally invasive surgeries.

\section{Conclusion}

Utilization of a digital protractor and a spirit level could provide an accurate estimation of stem anteversion in cementless THA. This technique can determine the intraoperative anteversion with a high precision and can be used with different stem handles in posterolateral approach.

\section{Abbreviations}

THA: Total hip arthroplasty; EKG: Electrocardiogram; ICC: Intra-class correlation coefficients; CT: Computed tomography; Cl: Confidence interval; SD: Standard deviation; $\mathrm{kg} / \mathrm{m}^{2}$ : Kilogram per square meter

\section{Acknowledgements}

We thank Andrew Sherratt and Richard Rice for their assistance with English language usage.

\section{Authors' contributions}

AP developed the study design, performed the surgery, data analysis and writing the manuscript. NP performed data collection, analysis and data interpretation. NK analyzed and interpreted the data. All authors read and approved the final manuscript.

\section{Funding}

No funding.

\section{Availability of data and materials}

The datasets used and analyzed in the study are available on request to the corresponding author.

\section{Ethics approval and consent to participate}

The Research Ethics Committee of Lampang Hospital reviewed and approved this study (EC code: 042/60). Written informed consent was obtained from all participants in the study. The procedures were in accordance with the ethical standards of the responsible committee on human experimentation and with the Declaration of Helsinki 2000.
Consent for publication

Not applicable.

\section{Competing interests}

The authors declare that they have no competing interests.

Received: 31 October 2020 Accepted: 25 December 2020

Published online: 07 January 2021

\section{References}

1. Yoshimine F. The safe-zones for combined cup and neck anteversions that fulfill the essential range of motion and their optimum combination in total hip replacements. J Biomech. 2006;39:1315-23. https://doi.org/10.1016/j. jbiomech.2005.03.008.

2. Wines AP, McNicol D. Computed tomography measurement of the accuracy of component version in total hip arthroplasty. J Arthroplasty. 2006;21:696-701. https://doi.org/10.1016/j.arth.2005.11.008.

3. Dorr LD, Malik A, Dastane M, Wan Z. Combined anteversion technique for total hip arthroplasty. Clin Orthop Relat Res. 2009;467:119-27. https://doi. org/10.1007/s11999-008-0598-4.

4. Dorr LD, Wan Z, Malik A, Zhu J, Dastane M, Deshmane P. A comparison of surgeon estimation and computed tomographic measurement of femoral component anteversion in cementless total hip arthroplasty. J Bone Joint Surg Am. 2009;91:2598-604.

5. Hirata M, Nakashima Y, Ohishi M, Hamai S, Hara D, Iwamoto Y. Surgeon error in performing intraoperative estimation of stem anteversion in cementless total hip arthroplasty. J Arthroplasty. 2013;28:1648-53. https:// doi.org/10.1016/j.arth.2013.03.006

6. Lee YK, Kim JW, Kim TY, Ha YC, Koo KH. Validity of the intra-operative measurement of stem anteversion and factors for the erroneous estimation in cementless total hip arthroplasty using postero-lateral approach. Orthop Traumatol Surg Res. 2018;104:341-6. https://doi.org/10.1016/j.otsr.2017.11. 023.

7. Meermans G, Goetheer-Smits I, Lim RF, Van Doorn WJ, Kats J. The difference between the radiographic and the operative angle of inclination of the acetabular component in total hip arthroplasty: use of a digital protractor and the circumference of the hip to improve orientation. Bone Joint J. 2015; 97-B:603-10. https://doi.org/10.1302/0301-620X.97B5.34781.

8. Echeverri S, Leyvraz PF, Zambelli PY, Jolles BM. Reliable acetabular cup orientation with a new gravity-assisted guidance system. J Arthroplasty. 2006;21:413-9. https://doi.org/10.1016/j.arth.2005.04.015.

9. Leone WA, Nevelos JE, Fonti F, Patel A. A new surgical instrument and technique designed to achieve more accurate component placement in total hip replacement. Tech Orthop. 2011;26:217-21.

10. Darrith B, Bell JA, Culvern C, Della Valle CJ. Can the use of an inclinometer improve the positioning of the acetabular component in total hip arthroplasty? Bone Joint J. 2018;100-B:862-6. https://doi.org/10.1302/0301620X.100B7.BJJ-2017-1607.R1

11. McDaniel G, Mitchell KL, Charles C, Kraus VB. A comparison of five approaches to measurement of anatomic knee alignment from radiographs. Osteoarthritis Cartilage. 2010;18:273-7. https://doi.org/10.1016/j.joca.2009.10. 005. 
12. Koo TK, Li MY. A guideline of selecting and reporting intraclass correlation coefficients for reliability research. J Chiropr Med. 2016;15:155-63. https:// doi.org/10.1016/j.jcm.2016.02.012.

13. Mukaka MM. Statistics corner: a guide to appropriate use of correlation coefficient in medical research. Malawi Med J. 2012;24:69-71.

14. Pongkunakorn A, Palawong P, Chatmaitri S, Phetpangnga N. Use of a digital protractor and a spirit level to determine the intraoperative anteversion of femoral component during cemented hip hemiarthroplasty: a prospective clinical trial. Arch Bone Jt Surg. 2019;7:314-20.

15. Howell SM, Chen J, Hull ML. Variability of the location of the tibial tubercle affects the rotational alignment of the tibial component in kinematically aligned total knee arthroplasty. Knee Surg Sports Traumatol Arthrosc. 2013; 21:2288-95. https://doi.org/10.1007/s00167-012-1987-5.

16. Siston RA, Daub AC, Giori NJ, Goodman SB, Delp SL. Evaluation of methods that locate the center of the ankle for computer-assisted total knee arthroplasty. Clin Orthop Relat Res. 2005;439:129-35.

\section{Publisher's Note}

Springer Nature remains neutral with regard to jurisdictional claims in published maps and institutional affiliations.

Ready to submit your research? Choose BMC and benefit from:

- fast, convenient online submission

- thorough peer review by experienced researchers in your field

- rapid publication on acceptance

- support for research data, including large and complex data types

- gold Open Access which fosters wider collaboration and increased citations

- maximum visibility for your research: over $100 \mathrm{M}$ website views per year

At BMC, research is always in progress.

Learn more biomedcentral.com/submissions 